\title{
Cannabinoids in the Treatment of Parkinson's Disease
}

\section{다 (i) $(\mathrm{)})$}

\author{
Authors \\ Florin Gandor, Georg Ebersbach
}

\author{
Affiliation \\ Neurologisches Fachkrankenhaus für Bewegungsstörungen \\ und Parkinson, Kliniken Beelitz GmbH, Beelitz-Heilstätten, \\ Germany \\ Key words \\ Parkinson's disease, THC, cannabinoids \\ Bibliography \\ DOI https://doi.org/10.1055/s-0043-115359 \\ Published online: 2017 \\ Neurology International Open 2017; 1: E307-E311 \\ (c) Georg Thieme Verlag KG Stuttgart · New York \\ ISSN 2511-1795 \\ Correspondence \\ Prof. Dr. med. Georg Ebersbach \\ Neurologisches Fachkrankenhaus für Bewegungsstörungen \\ und Parkinson \\ Kliniken Beelitz GmbH \\ Straße nach Fichtenwalde 16 \\ 14547 Beelitz-Heilstätten \\ Germany \\ ebersbach@kliniken-beelitz.de
}

\begin{abstract}
Due to the changing legal status of medical cannabis and derivatives in numerous countries, this therapeutic option has moved into the field of public debate. Neurologists treating patients with idiopathic Parkinson's disease are increasingly confronted with questions regarding cannabis as a treatment alternative, especially for levodopa-resistant Parkinson's symptoms. A number of single case reports and case series suggested improvement of Parkinsonian symptoms after cannabinoid intake, but the small number of available randomized clinical trials failed to reproduce the extent of these findings. Only one trial found a reduction of levodopa-induced dyskinesia with cannabinoid treatment, the remaining three trials showed no effect on Parkinsonian symptoms. This article gives an overview on the effects of cannabis, and reviews experimental and clinical trials studying the effects of cannabinoids in idiopathic Parkinson's disease.
\end{abstract}

\section{Introduction}

At the latest since the resolution of the German parliament on January 19, 2017 to ament the German Narcotic Drugs Act (Betäubungsmittelgesetz, BtMG ) with regard to the treatment of severely ill patients with high-quality cannabis medications (documents $18 / 8965$ and 18/10902 of the German parliament), there has been growing public interest in the therapeutic properties of cannabis. Until then, an exemption of the Federal Institute for Drugs and Medical Devices (Bundesinstitut für Arzneimittel und Medizinprodukte, BfArM) was required to allow for treating patients with cannabis products. Until 2016, such exemptions had been issued for about 1000 patients (www.bundestag.de). While so far patients had to pay for this treatment themselves, the new amendment now regulates the covering of treatment costs by health insurance companies.

Besides the change of the legal status, scientific interest in the potential therapeutic properties of cannabis has been growing, driven by advances in the understanding of the endocannabinoid system.
The isolation of cannabinoid receptors and endogenous cannabinoids in the nervous system by Raphael Mechoulam [1] and other groups and the discovery that the endocannabinoid system is capable of modulating numerous physiological processes, such as pain, eating behavior, memory, and mood [2,3] have paved the way for systematic research into the effects of cannabis on a variety of chronic diseases [4-7]. Data from clinical studies supported a role of cannabis and endocannabinoids in the treatment of specific symptoms, such as spasticity and central or spasticity-associated pain in patients with multiple sclerosis, chemotherapy-induced nausea, and anorexia [7]. Until recently, the only medicines of this class approved in Germany were the combination drug Sativex ${ }^{\circledR}$ as an add-on therapy for adult multiple-sclerosis patients with moderate to severe spasticity, and the synthetically manufactured tetrahydrocannabinol analogue nabilone (Canemes $\left.{ }^{\circledR}\right)$ for the treatment of adult cancer patients suffering from chemotherapy-induced nausea. Since March 10, 2017 cannabis flowers and 


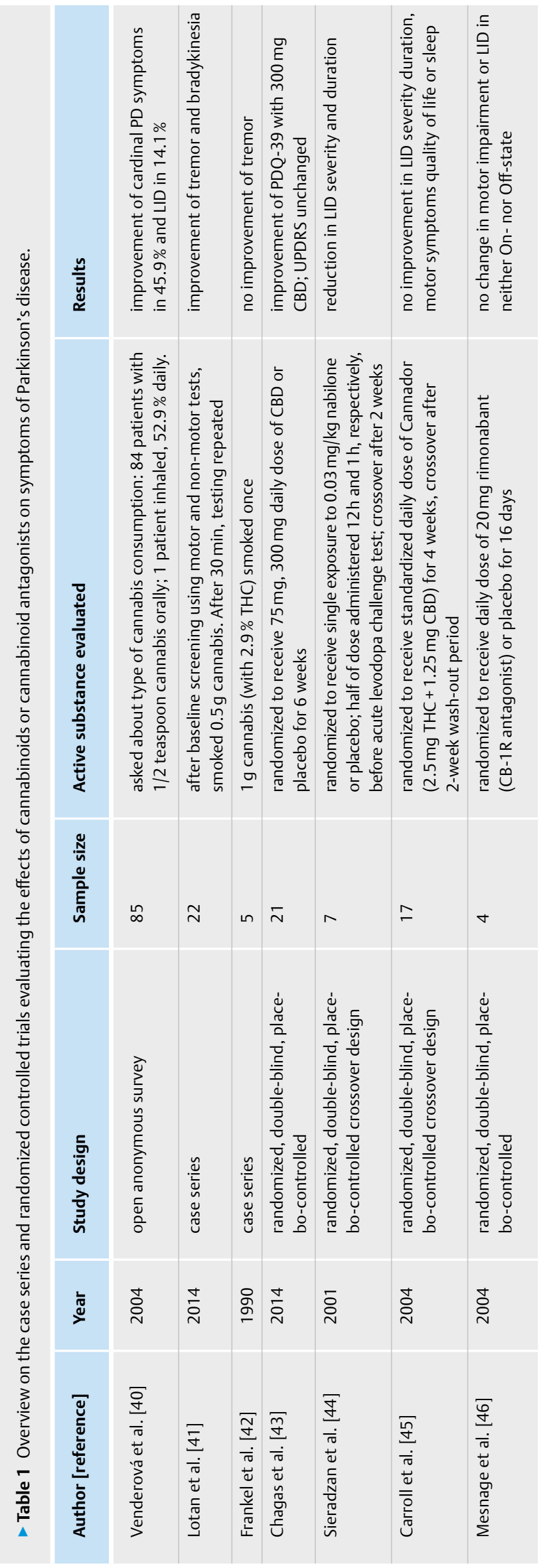

their extracts can be prescribed on a narcotic drug prescription form without limitation to specific indications [8].

The discovery of high concentrations of cannabinoid receptors in the basal ganglia triggered an increasing interest in the therapeutic potential of cannabinoids for the treatment of Parkinson's disease (PD) and other movement disorders. Public awareness of this topic was raised by anecdotal reports of considerable improvement of PD symptoms after cannabis consumption that were shared via social networks and published in the general press. For example, Larry Smith, a US-American PD patient claiming improvement of his dyskinesia with cannabis consumption, attracted broader public attention via YouTube ${ }^{\mathrm{TM}}$ [9]. In Germany, cannabis consumption to alleviate PD symptoms gained attention when the topic was raised in the German TV drama series "Lindenstrasse" (the German equivalent to the British TV drama series "Coronation Street") [10].

\section{Cannabis and the Endocannabinoid System}

Cannabis is a mixture of more than 60 substances, referred to as phytocannabinoids due to their plant origin (as opposed to endocannabinoids produced by the human body). The main active constituents of cannabis are the psychotropic cannabinoid delta9-tetrahydrocannabinol (THC) and the non-psychotropic cannabinoid cannabidiol (CBD). These substances were isolated in the $1960 \mathrm{~s}$ and proven to be active components of cannabis $[1,11]$. In the 1990 s, the two most important receptors - the cannabinoid receptor 1 (CB-1R) [12] and the cannabinoid receptor 2 (CB-2R) [13] - and their endogenous ligands, such as anandamide and 2-arachidonylglycerol (2-AG), and hence the endocannabinoid system (ECS) were discovered.

CB-1R is primarily located in the nervous system (except for the thalamus and brain stem), with high concentrations in the hippocampus, the association cortex, cerebellum, basal ganglia, and spinal cord (here with high concentration in the dorsal roots), and peripheral nerves [7]. CB-2R is expressed in the gastrointestinal tract, in lymphatic tissue and peripheral nervous system. However, in 2014 it was shown that CB-2R is also expressed in the CNS, primarily in neurons of the dorsal nucleus of the vagus nerve, the nucleus ambiguus, in the spinal trigeminal nucleus, and on microglia [14-16].

CB-1R and CB-2R are $G$ protein-coupled receptors and via the $G_{0} / G_{i}$ unit inhibit the activity of the adenyl cyclase, thereby influencing the release of excitatory neurotransmitters, such as glutamate, dopamine and acetylcholine. In addition, other transmitter systems, such as the NMDA ( $\mathrm{N}$-methyl-D-aspartate) and the serotonin, the opioid and GABA ( $\gamma$-aminobutyric acid) systems are also modulated via indirect mechanisms [7]. Furthermore, the mitogen-activated protein kinase/extracellular signal-regulated kinase (MAPK/ERK) pathway is activated via the $G_{\beta \gamma}$ complex [17-19], a pathway that has regulatory properties regarding cell development, cell differentiation and apoptosis [20].

The structural analysis of cannabinoid receptors ultimately paved the way for the development of synthetic cannabinoids. Today, several cannabinoid-based preparations are available for medicinal use ( $\triangleright$ Table $\mathbf{1})$. 


\section{Parkinson's Disease and Neuroprotection in Experimental Studies}

In the late 1960 s and early 1970 s, early animal studies demonstrated an effect of cannabinoids on the catecholaminergic and dopaminergic systems [21,22]. CB-1R and the endocannabinoid ligands anandamide and 2-AG occur in high concentrations in the dopaminergic system, including the striatum [23], where they modulate dopaminergic transmission as a retrograde feedback system on presynaptic glutamatergic and GABAergic nerve endings. In-vitro studies in the late 1970 s generated conflicting evidence, demonstrating both an increase [24] and a dose-dependent decrease of dopamine synthesis [25] and release [22]. In-vivo studies showed an increase in dopamine release in the prefrontal cortex, striatum, but also in the nucleus accumbens. Thus, an increased firing rate of dopaminergic neurons after acute THC exposure can be assumed, resulting in augmented dopamine synthesis and release. Interestingly, acute and chronic THC exposure seems to result in different effects on neuronal firing rate, transmitter synthesis, transmitter release and reuptake within the dopaminergic system [26].

An increase in ECS activity was detected both in a PD animal model and in human tissue analyses from PD patients [27], including an upregulation of cannabinoid receptors [28, 29], an accumulation of cannabinoid receptor agonists $[30,31]$ and a reduction in their degradation [32]. This adaptation of the ECS was reversed by chronic levodopa substitution in an animal model [33].

With regards to the effect of $C B-1 R$ on motor function, experimental studies yielded heterogeneous and partially conflicting results. Direct activation of CB-1R reduced dopamine release and resulted in an increase in bradykinesia, shown in the MPTP (1-methyl-4-phenyl-1,2,3,6-tetrahydropyridine) animal model of PD [34]. Others reported improvement of motor impairment with cannabinoid receptor agonists, possibly due to receptor-independent mechanism of action [35, 36]. Furthermore, alleviation of levodopa-induced dyskinesia has been reported for cannabinoid receptor agonists and antagonists [31,37].

In addition, ECS activation may confer neuroprotective such as direct receptor-independent mechanisms [38], activation of anti-inflammatory cascades in glial cells via CB-2R $[39,40]$, and anti-glutamatergic and thus anti-excitotoxic properties [41].

\section{Clinical Research}

Numerous case series and single case reports concluded that cannabinoids might have potential beneficial effects on PD symptoms.

In a large survey with 339 Czech PD patients, about $25 \%$ of the respondents stated to regularly consume cannabis as an add-on therapy. Of these 85 patients, 39 (46\%) reported general improvement of their PD symptoms. 26 patients (31\%) reported a reduction of resting tremor, 38 patients ( $45 \%$ ) an improvement of bradykinesia, 32 patients (38\%) a decrease in muscle rigidity, and 12 patients (14\%) reduction of levodopa-induced dyskinesia [42].

An observational study from Israel involving 22 PD patients showed a reduction of the Unified Parkinson's Disease Rating Scale (UPDRS) motor score of $30 \%$ thirty minutes after patients smoked cannabis. In addition, pain and sleep quality improved under long- term therapy with cannabis [43]. A very early and small case series from London with 5 PD patients evaluated the effect of cannabis smoking on resting tremor but found no improvement [44].

In contrast to the clearly positive effects described in single case reports and case series, data from randomized placebo-controlled trials (RCTs) on effects on PD motor symptoms are less encouraging. So far, 4 RCTs evaluating the effects of cannabinoids on altogether 49 PD patients have been published.

In a study by Chagas et al., PD patients were randomized to receive CBD daily in doses of either $75 \mathrm{mg}, 300 \mathrm{mg}$, or placebo, with 7 patients randomized into each group. After 6 weeks, motor function (UPDRS motor score) and quality of life (Parkinson's Disease Questionnaire - PDQ-39) were assessed and compared to baseline. The improvement in PDQ-39 sum score was significantly higher in patients treated with $300 \mathrm{mg} /$ day of CBD, while UPDRS scores did not differ between groups [45].

A study from Manchester evaluated the effect of nabilone, a CB-1R and CB-2R agonist, on levodopa-induced dyskinesia in 7 patients in a crossover design. A total dose of $0.03 \mathrm{mg} / \mathrm{kg}$ body weight was administered with half the dose $12 \mathrm{~h}$ before the remainder $1 \mathrm{~h}$ before an acute levodopa challenge, which then was repeated 14 days later when groups had been crossed over. Dyskinesia duration and severity were significantly reduced in the nabilone group. However, no change in the severity of PD symptoms and no difference in motor improvement after the acute levodopa challenge were observed. In the nabilone group, 5 of 7 patients experienced mild sedation, dizziness, hyperacusis, disorientation, and scenic visual hallucinations [46].

Caroll et al. studied the effect of Cannador ${ }^{\circledR}$, a whole-plant extract with defined THC content and a THC to CBD ratio of about 2:1, on 17 PD patients. Over a period of 4 weeks, increasing doses of Cannador ${ }^{\circledR}$, were administered b.i.d., up to a maximum THC daily dose of $0.25 \mathrm{mg} / \mathrm{kg}$. Despite the double-blind design, $71 \%$ of patients correctly identified their respective treatment arm. Neither levodopa-induced dyskinesia (assessed with UPDRS dyskinesia score and Rush Dyskinesia Rating Scale) nor UPDRS motor scores, PDQ-39 or sleep quality improved. In contrast, a (non-significant) trend towards an increase of dyskinesia severity with Cannador ${ }^{\circledR}$ treatment was observed [47].

In 2004, Mesnage et al. studied the CB-1R antagonist rimonabant, among others, and its effect on PD symptoms. Over a period of 16 days, 4 patients received $20 \mathrm{mg} /$ day of rimonabant. At the end of period, neither UPDRS motor scores nor UPDRS dyskinesia scores changed significantly [48].

To date, only one other study investigating the effect of CBD on PD tremor has been registered (NCT02818777), aiming at recruiting 60 patients.

\section{Psychotropic and Cardiovascular Side Effects}

Considering the increased prevalence of psychotic symptoms in patients with idiopathic Parkinson's disease, psychotropic effects of cannabis and cannabinoids are of special interest (Chang and Fox 2016). In a study by Sieradzan and colleagues, 5 of 7 PD patients treated with the THC analog nabilone experienced psychotropic 
side effects such as scenic visual hallucinations [46]. In the study of Lotan et al., 6 of the initially included 28 patients (21\%) with an average age of 65 years dropped out due to psychotic symptoms following cannabis consumption [43].

The primary active component responsible for the psychotropic effect of cannabis is THC. In clinical studies investigating the effects of CBD, no psychotic side effects were observed [45]. In an open-label study, 6 PD patients with psychiatric plus symptoms, such as illusions and hallucinations, and minus symptoms, such as withdrawal and depression, received CBD over a period of 4 weeks. Treatment was started with an initial daily dose of $150 \mathrm{mg}$ and gradually increase over a period of 1 month up to a maximum daily dose of $400 \mathrm{mg}$ [49]. The authors reported a significant reduction in psychotic symptoms, as measured with the Parkinson Psychosis Questionnaire (PPQ) and the Brief Psychiatric Rating Scale (BPRS).

Apart from psychotropic effects, cannabinoids are associated with adverse cardiovascular events. Non-motor PD symptoms include orthostatic hypotension caused by sympathetic cardiac denervation, among others [50]. Similarly, cannabis consumption can also lead to an orthostatic drop in blood pressure and even orthostatic syncope [51]. Due to sympathetic cardiac denervation, the ability to counteract a drop in blood pressure by increasing the heart rate is limited in PD patients. This, in turn, may intensify the impact of cannabinoids on orthostatic dysregulation. The study of Sieradzan et al. detected an orthostatic drop in systolic blood pressure in all patients. One patient in the nabilone group was unable to continue the study due to symptomatic orthostatic hypotension [46]. Furthermore, the increased sympathetic activity with cannabis consumption results in an increased myocardial oxygen demand. In patients with preexisting angina pectoris, exercise symptoms of myocardial hypoxia occur earlier with cannabis consumption $[52,53]$. In addition, the risk of myocardial infarction is increased by 1 to 4.8 fold in cannabis users [54, 55]. With the possibility of cardiac comorbidities in PD patients, these adverse events should receive additional attention.

\section{Conclusion}

In summary, the positive effects of cannabinoid consumption on motor symptoms in patients with Parkinson's disease described in single case reports and case series have not been confirmed by the few placebo-controlled studies available as yet. Results of studies on cannabinoids for the treatment levodopa-induced dyskinesia have been inconsistent. The postulated beneficial effects of cannabinoids are opposed by potential side effects, such as hallucinations and orthostatic hypotension, which require special attention in $\mathrm{PD}$ patients.

Therefore, the clinical use of cannabinoids in patients with Parkinson's disease should be preceded by careful individual risk-benefit assessments. Currently, it should be limited to symptoms for which positive effects can be expected from other indications for cannabinoids, such as refractory pain or sleep disorders. In view of the extended approval of cannabinoids, further controlled studies are urgently needed to provide data that support evidence-based treatment recommendations, and to increase confidence in the safety of prescribing cannabinoid therapies.

\section{Conflict of Interest}

Dr. Florin Gandor, MD: Fees for advisory board participation: AbbVie Pharma. Lecture fees: MERZ Pharma, Prof. Georg Ebersbach, MD: Consultancy fees: AOK Nordost. Fees for advisory board participation: AbbVie Pharma, Grünenthal Pharma, Neuroderm Inc., GE Healthcare GmbH. Lecture fees: AbbVie Pharma, BIAL Pharma, Desitin Pharma, Licher GmbH, TEVA Pharma, UCB Pharma, Zambon Pharma, Medtronic, Royalties: Kohlhammer Verlag

\section{References}

[1] Gaoni Y, Mechoulam R. Isolation, structure, and partial synthesis of an active constituent of hashish. J Am Chem Soc 1964; 86: 1646-1647

[2] Di Marzo V, Melck D, Bisogno T et al. Endocannabinoids: Endogenous cannabinoid receptor ligands with neuromodulatory action. Trends Neurosci 1998; 21: 521-528

[3] Parker LA, Rock EM, Limebeer CL. Regulation of nausea and vomiting by cannabinoids and the endocannabinoid system. Eur J Pharmacol 2014; 722: 134-146

[4] Pacher P, Kunos G. Modulating the endocannabinoid system in human health and disease - Successes and failures. FEBS J 2013; 280: 1918-1943

[5] Kendall DA, Yudowski GA, Wang $\mathrm{H}$ et al. Cannabinoid receptors in the central nervous system: Their signaling and roles in disease. Front Cell Neurosci 2017; 10: 1-10

[6] Scotter EL, Abood ME, Glass M. The endocannabinoid system as a target for the treatment of neurodegenerative disease. $\mathrm{Br}$ J Pharmacol 2010; 160: 480-498

[7] Koppel BS, Brust JCM, Fife T et al. Systematic review: Efficacy and safety of medical marijuana in selected neurologic disorders. Neurology 2014; 82: 1556-1563

[8] 2017; Cannabisagentur. www.bfarm.de/DE/Bundesopiumstelle/ Cannabis/Cannabisagentur/_node.html

[9] 2016; Ride with Larry. https://www.youtube.com/watch?v=LHvPIXGsrHk\&list= PL6wHuRfu1deQ2BZ_yLddvdQfKEJbjFkLg

[10] 2016; Lindenstrasse, Folge 1581. http://www1.wdr.de/daserste/ lindenstrasse/folgen/2016/ende-und-anfang-100 _compage-4.html

[11] Mechoulam R, Shvo Y, Hashish I. The structure of cannabidiol. Tetrahedron 1963; 19: 2073-2078

[12] Matsuda LA, Lolait S], Brownstein M] et al. Structure of a cannabinoid receptor and functional expression of the cloned cDNA. Nature 1990; 346: 561-564

[13] Munro S, Thomas KL, Abu-Shaar M. Molecular characterization of a peripheral receptor for cannabinoids. Nature 1993; 365: 61-65

[14] Rogers N. Cannabinoid receptor with an "identity crisis" gets a second look. Nat Med 2015; 21: 966-967

[15] Onaivi ES. Neuropsychobiological evidence for the functional presence and expression of cannabinoid CB2 receptors in the brain. Neuropsychobiology 2006; 54: 231-246

[16] Van Sickle MD, Duncan M, Kingsley PJ et al. Identification and functional characterization of brainstem cannabinoid CB2 receptors. Science 2005; 310: 329-332

[17] Valjent E, Pagès $C$, Rogard $M$ et al. Delta 9-tetrahydrocannabinol-induced MAPK/ERK and Elk-1 activation in vivo depends on dopaminergic transmission. Eur J Neurosci 2001; 14: 342-352

[18] Moranta D, Esteban S, García-Sevilla JA. Acute, chronic and withdrawal effects of the cannabinoid receptor agonist WIN55212-2 on the sequential activation of MAPK/Raf-MEK-ERK signaling in the rat cerebral frontal cortex: Short-term regulation by intrinsic and extrinsic pathways. J Neurosci Res 2007; 85: 656-667 
[19] Howlett AC, Blume LC, Dalton GD. CB(1) cannabinoid receptors and their associated proteins. Curr Med Chem 2010; 17: 1382-1393

[20] Cargnello M, Roux PP. Activation and function of the MAPKs and their substrates, the MAPK-activated protein kinases. Microbiol Mol Biol Rev 2011; 75: 50-83

[21] Garriott JC, King LJ, Forney RB et al. Effects of some tetrahydrocannabinols on hexobarbital sleeping time and amphetamine induced hyperactivity in mice. Life Sci 1967; 6: 2119-2128

[22] Howes ], Osgood P. The effect of delta9-tetrahydrocannabinol on the uptake and release of 14C-dopamine from crude striatal synaptosoma; preparations. Neuropharmacology 1974; 13: 1109-1114

[23] Herkenham M, Lynn AB, de Costa BR et al. Neuronal localization of cannabinoid receptors in the basal ganglia of the rat. Brain Res 1991; 547: 267-274

[24] Hershkowitz M, Szechtman H. Pretreatment with delta 1-tetrahydrocannabinol and psychoactive drugs: Effects on uptake of biogenic amines and on behavior. Eur J Pharmacol 1979; 59: 267-276

[25] Bloom AS, Dewey WL. A comparison of some pharmacological actions of morphine and delta9-tetrahydrocannabinol in the mouse. Psychopharmacology (Berl) 1978; 57: 243-248

[26] Bloomfield MAP, Ashok AH, Volkow ND et al. The effects of $\Delta 9$-tetrahydrocannabinol on the dopamine system. Nature 2016; 539: 369-377

[27] Fernández-Ruiz J, Moreno-Martet M, Rodríguez-Cueto $C$ et al. Prospects for cannabinoid therapies in basal ganglia disorders. $\mathrm{Br}$ J Pharmacol 2011; 163: 1365-1378

[28] Gómez-Gálvez Y, Palomo-Garo C, Fernández-Ruiz ] et al. Potential of the cannabinoid CB2 receptor as a pharmacological target against inflammation in Parkinson's disease. Prog Neuro-Psychopharmacology Biol Psychiatry 2016; 64: 200-208

[29] Lastres-Becker I, Cebeira M, de Ceballos ML et al. Increased cannabinoid CB1 receptor binding and activation of GTP-binding proteins in the basal ganglia of patients with Parkinson's syndrome and of MPTP-treated marmosets. Eur J Neurosci 2001; 14: 1827-1832

[30] Di Marzo V, Hill MP, Bisogno T et al. Enhanced levels of endogenous cannabinoids in the globus pallidus are associated with a reduction in movement in an animal model of Parkinson's disease. FASEB J 2000; 14: $1432-1438$

[31] van der Stelt M, Fox SH, Hill M et al. A role for endocannabinoids in the generation of parkinsonism and levodopa-induced dyskinesia in MPTP-lesioned non-human primate models of Parkinson's disease. FASEB J 2005; 19: 1140-1142

[32] Gubellini P, Picconi B, Bari M et al. Experimental parkinsonism alters endocannabinoid degradation: implications for striatal glutamatergic transmission. J Neurosci 2002; 22: 6900-6907

[33] Maccarrone M, Gubellini P, Bari M et al. Levodopa treatment reverses endocannabinoid system abnormalities in experimental parkinsonism. J Neurochem 2003; 85: 1018-1025

[34] Meschler JP, Howlett AC, Madras BK. Cannabinoid receptor agonist and antagonist effects on motor function in normal and 1-methyl-4-phenyl-1,2,5,6-tetrahydropyridine (MPTP)-treated non-human primates. Psychopharmacology (Berl) 2001; 156: 79-85

[35] Kreitzer AC, Malenka RC. Endocannabinoid-mediated rescue of striatal LTD and motor deficits in Parkinson's disease models. Nature 2007; 445: 643-647

[36] Fernandez-Espejo E, Caraballo I, Rodriguez de Fonseca F et al. Experimental parkinsonism alters anandamide precursor synthesis, and functional deficits are improved by AM404: A modulator of endocannabinoid function. Neuropsychopharmacol 2004; 29: 1134-1142
[37] Fox SH, Henry B, Hill M et al. Stimulation of cannabinoid receptors reduces levodopa-induced dyskinesia in the MPTP-lesioned nonhuman primate model of Parkinson's disease. Mov Disord 2002; 17: $1180-1187$

[38] Carroll CB, Zeissler M-L, Hanemann CO et al. $\Delta 9$-tetrahydrocannabinol $(\triangle 9-T H C)$ exerts a direct neuroprotective effect in a human cell culture model of Parkinson's disease. Neuropathol Appl Neurobiol 2012; 38: 535-547

[39] Klein TW. Cannabinoid-based drugs as anti-inflammatory therapeutics. Nat Rev Immunol 2005; 5: 400-411

[40] Lastres-Becker I, Molina-Holgado F, Ramos JA et al. Cannabinoids provide neuroprotection against 6-hydroxydopamine toxicity in vivo and in vitro: Relevance to Parkinson's disease. Neurobiol Dis 2005; 19 : 96-107

[41] Fernández-Ruiz J, García C, Sagredo O et al. The endocannabinoid system as a target for the treatment of neuronal damage. Expert Opin Ther Targets 2010; 14: 387-404

[42] Venderová K, Růzicka E, Vorísek $V$ et al. Survey on cannabis use in Parkinson's disease: subjective improvement of motor symptoms. Mov Disord 2004; 19: 1102-1106

[43] Lotan I, Treves TA, Roditi Y et al. Cannabis (Medical Marijuana) Treatment for motor and non-motor symptoms of Parkinson disease. Clin Neuropharmacol 2014; 37: 41-44

[44] Frankel JP, Hughes A, Lees AJ et al. Marijuana for parkinsonian tremor. J Neurol Neurosurg Psychiatry 1990; 53: 436

[45] Chagas MH, Zuardi AW, Tumas V et al. Effects of cannabidiol in the treatment of patients with Parkinson's disease: An exploratory double-blind trial. J Psychopharmacol 2014; 28: 1088-1098

[46] Sieradzan KA, Fox SH, Hill M et al. Cannabinoids reduce levodopa-induced dyskinesia in Parkinson's disease: A pilot study. Neurology 2001; 57: 2108-2111

[47] Carroll CB, Bain PG, Teare L et al. Cannabis for dyskinesia in Parkinson disease: A randomized double-blind crossover study. Neurology 2004; 63: $1245-1250$

[48] Mesnage V, Houeto JL, Bonnet AM et al. Neurokinin B, neurotensin, and cannabinoid receptor antagonists and Parkinson disease. Clin Neuropharmacol 2004; 27: 108-110

[49] Zuardi AW, Crippa JAS, Hallak JEC et al. Cannabidiol for the treatment of psychosis in Parkinson's disease. J Psychopharmacol 2009; 23: 979-983

[50] Seppi K, Weintraub D, Coelho M et al. The Movement Disorder Society Evidence-Based Medicine Review Update: Treatments for the non-motor symptoms of Parkinson's disease. Mov Disord 2001; 26: (Suppl 3): $\$ 42-\$ 80$

[51] Sidney S. Cardiovascular consequences of marijuana use. J Clin Pharmacol 2002; 42: 64S-70S

[52] Prakash R, Aronow WS, Warren M et al. Effects of marihuana and placebo marihuana smoking on hemodynamics in coronary disease. Clin Pharmacol Ther 1975; 18: 90-95

[53] Aronow WS, Cassidy J. Effect of marihuana and placebo-marihuana smoking on angina pectoris. N Engl J Med 1974; 291: 65-67

[54] Jouanjus E, Lapeyre-Mestre M, Micallef J. French Association of the Regional Abuse and Dependence Monitoring Centres (CEIP-A) Working Group on Cannabis Complications * Cannabis Use: Signal of increasing risk of serious cardiovascular disorders. J Am Heart Assoc 2014; 3: e000638-e000638

[55] Mittleman MA, Lewis RA, Maclure M et al. Triggering myocardial infarction by marijuana. Circulation 2001; 103: 2805-2809 